\title{
Turismo, patrimonialização e o tombamento estadual dos bens naturais de Belém do Pará (Brasil)
}

\author{
Tourism, patrimonialization and the state protection of the natural assets in Belém \\ do Pará (Brazil)
}

Cleber Gomes da Silva (SILVA, C. G. da)*

RESUMO - Este artigo apresenta uma análise dos tombamentos de bens naturais, ocorridos em Belém do Pará desde a década de 1980. Promove uma reflexão acerca da relação entre turismo, natureza e cultura. No aspecto metodológico, foi realizado um estudo bibliográfico e documental. Como resultado, se considera que o patrimônio cultural da região não pode ser refletido somente no testemunho arquitetônico, como determinantes da narrativa e da memória da região, em sua apropriação pelo turismo em um processo de patrimonialização. Considera-se também que o maior problema da questão do tombamento dos bens naturais está nas reais intencionalidades da adoção desse instrumento e converge para suas consequências como mecanismo ao mesmo tempo de valorização cultural e de conservação da natureza. De outra maneira, é importante levar em conta como as sobreposições com a política ambiental têm prejudicado o desenvolvimento de ações relativas a memória dos lugares e de sua importância para o turismo. Finalmente, é necessária uma grande integração entre órgãos, esferas e políticas a fim de garantir o reconhecimento, proteção e lazer dessas áreas.

Palavras-chave: Turismo; Patrimonialização; Bens naturais; Tombamento.

ABSTRACT - This article shows an analysis of the state protection of natural assets in Belém do Pará since the 1980s. It promotes a reflection on the relationship among tourism, nature and culture. In the methodological aspect, a bibliographic and documentary study was carried out. As result, it is considered that the cultural heritage of the region cannot be reflected only in the architectural testimony, as determinants of the narrative and the memory of the region, in an appropriation by tourism in a process of patrimonialization. It is also considered that the greatest problem of the state protection of natural assets lies in the real intentions of the adoption of this instrument and it converges to its consequences as a mechanism of cultural valorization and nature conservation. Otherwise, it is important to consider how overlaps with environmental policy have hampered the development of actions concerning the memory of places and their importance as places of memory. Finally, it is necessary the greater integration among organs, spheres and policies in order to guarantee the recognition, protection and enjoyment of these assets.

Key words: Tourism; Patrimonialization; Natural assets; State protection.

\footnotetext{
* Formação: Graduação em Turismo (Bacharelado) pela Universidade Federal do Pará (UFPA). Especialização em Gestão Governamental pelo Centro Universitário do Pará/Escola de Governo. Mestrado em Gestão de Recursos Naturais e Desenvolvimento Local na Amazônia PPGEDAM/Universidade Federal do Pará - UFPA. Doutorando em Geografia, vinculado à Universidade Federal do Pará (UFPA). Atividade profissional: Gerente de Estatística e Informação junto à Secretaria de Estado de Turismo - SETUR e Docente da Faculdade Pan Amazônica. E-mail: gestor.gov@ hotmail.com
} 


\section{INTRODUÇÃO}

Neste trabalho se objetivou analisar como a natureza é apropriada pelo turismo, a partir do seu reconhecimento como bem cultural na Amazônia. Dessa maneira pretendese contribuir para uma reflexão sobre a relação entre natureza, cultura e o turismo, através do processo de patrimonialização de bens naturais em Belém do Pará.

O reconhecimento do valor cultural da natureza pode ser compreendido como um subproduto da forma de ocupação da Amazônia, que inicialmente seguiu às margens de rios e contribuiu diretamente para a formação do espaço urbano dessa região.

Os eventos de ocupação, povoamento e exploração da natureza deixaram os vestígios de uma memória. Tal como demonstra Pierre Nora (1993), a memória é revestida de uma aura simbólica pela imaginação, movida por uma vontade memorialista. A memória é o vivido e podem ser objetos materiais, concretos, abstratos, simbólicos e funcionais, o que se perpetua de outro tempo em uma sociedade cada vez mais desritualizada.

Especialmente na Amazônia, o bem natural, se apresenta como experiência entrelaçada e inseparável do homem e seu espaço. Conforme discute Tavares (2011), no período entre 1580 e 1640 a ocupação da embocadura do rio Amazonas, com a fundação de Belém, em 1616, pode ser contextualizada em uma luta internacional por territórios estratégicos para exploração e comércio de especiarias.

A ocupação da região também pode ser relacionada à exploração da borracha, cuja expansão, marcada pela rede de aviamento e exploração do trabalho nos seringais aconteceu pelos vales de rios (CASTRO, 2008). Além disso, a abertura de rodovias e a implantação de grandes projetos agropecuários, minerais, hidrelétricos produziram grandes mudanças nas relações de produção (CORRÊA, 1987). Nessa perspectiva, tornou-se explícito o papel de grandes corporações na exploração de recursos naturais na região.

Entretanto, o rio, a flora, a fauna e o solo não podem ser observados somente como mercadorias, pois se manifestam constantemente como espaços vividos (LEFEBVRE, 2013). Mas quando se reconhece um bem natural qual valor está sendo atribuído? Assim toma-se o caso dos bens naturais tombados entre 1982 e 1994 pelo governo estadual do Pará, num tentativa de discutir a relevância assumida mediante as 
políticas patrimoniais, em especial, no município de Belém e que formas esses bens assumem no turismo, enquanto espaços concebidos.

Desse modo, apresenta-se uma revisão sobre a relação entre natureza, patrimônio cultural e turismo, sob a perspectiva da produção do espaço (LEFEBVRE, 2013) contextualizando os casos de tombamento de bens naturais em Belém do Pará. Em seguida, no artigo se descreve e analisa o papel dos bens protegidos, sobretudo no que tange às formas de apropriação turística dos objetos pesquisados.

\section{METODOLOGIA}

O presente estudo refere-se a uma pesquisa exploratória sobre os bens naturais tombados em Belém do Pará. Para a consecução dos resultados da pesquisa foram realizadas pesquisas bibliográfica e documental, com suporte de visitas de campo, aos bens tombados, realizadas em 2017 e 2018.

No plano metodológico, abordam-se técnicas de pesquisa que se fundamentaram no levantamento preliminar de referências bibliográficas sobre os objetos estudados. Porém, essa pesquisa foi consubstanciada pelo caráter empírico de observações realizadas in loco e evidenciadas a partir de contato direto. Para consolidar o trabalho foram realizadas consultas a documentos públicos e ao livro de tombo de Bens Naturais do estado do Pará (PARÁ, 1990), contemplando inscrições desde a década de 1990.

Após essa etapa, realizou-se uma incursão nos bens patrimonializados, com observação e anotação dos usos e serviços relacionados ao turismo. A partir da organização das informações e do confrontamento com as teorias discutidas elaborou-se a análise e as considerações finais.

\section{NATUREZA, PATRIMÔNIO CULTURAL E TURISMO}

Quando Milton Santos (2014, p. 129-140) abordou a questão da diversificação da natureza, apresentou subsídios fundamentais para compreensão dos processos inerentes a conversão da natureza em patrimônio cultural. Para o autor, a importância 
das feições naturais do território ainda influencia na maneira como ocorre a divisão do trabalho e aplica o conceito de rugosidades ao que fica do passado como espaço construído, paisagem, formas isoladas ou arranjos que trazem os restos de divisões do trabalho.

Esse processo dialético pode ser entendido como as duas faces do movimento de que submete a natureza ao mercado e a necessidade de proteção de um bem natural. Haesbaert (2006, p. 22) afirma que a reprodução do capital, a aceleração do ciclo produtivo e a dinâmica de exclusão "joga uma massa enorme de pessoas em circuitos de mobilidade compulsória na luta pela sobrevivência." Esse fenômeno, de alguma forma também gera uma espécie de alienação da natureza ou de seu valor de uso, que aos poucos deixou de ser acessível a todos.

Nessa oposição de intencionalidades, hegemoniza-se um valor de troca capaz de transformar o espaço de reprodução diária, a casa e a terra em mercadorias, como observado em Harvey (2016). Desse modo, "o espaço também se tornou produto do mercado, é a sua raridade que une os homens." (SANTOS, 2009, p. 34). O natural se constituiu como meio, essência e finalidade da produção do espaço regional.

Na perspectiva da produção do espaço, Lefebrve (2013, p. 127) argumenta que a natureza não pode produzir e o que ela cria de modo algum são produtos. Em suas inúmeras publicações, esse autor revela, sobretudo, diversos conceitos que giram em torno da produção do espaço e suas implicações na sociedade. Através de uma tríade dialética articula a noção de prática espacial (produção, reprodução, localizações e conjuntos espaciais característicos de cada formação social), representação do espaço (ordem de relações, signos e códigos) e espaço de representação (simbolismo e/de complexos codificados), permitindo analisar o real em seu conteúdo abstrato. Tenta evidenciar as relações simultâneas não capturadas pela forma.

Schmid (2012), explica que na abordagem de Lefebvre há uma dupla noção de produção: a produção de objetos e mercadorias capazes de gerar um mundo objetivo e a produção do espaço como condição da reprodução da vida social. Assim, a reprodução se realiza no espaço concreto como condição a acumulação, envolvendo a compreensão da reprodução do espaço social como necessidade do modo de produção capitalista em sua fase de realização, enfim não se restringe a produção das coisas, mas a reprodução de relações sociais de produção. 
Nesse sentido, Giddens (1991, p. 21-22) alerta que:

O caráter de rápida transformação da vida social moderna não deriva essencialmente do capitalismo, mas do impulso energizante de uma complexa divisão de trabalho, aproveitando a produção para as necessidades humanas através da exploração industrial da natureza. Vivemos numa ordem que não é capitalista, mas industrial.

A racionalidade da produção consiste em dispor uma série de fatos sucessivos em vista a um certo objetivo. Todavia, Lefebvre (2013, p. 129), ressalta que:

El espacio(social) no es una cosa entre las cosas, um producto cualquiera entre los produtos: más bien envuelve as las cosas producidas y compreende sus relaciones em su coexistência y simultaneidad: em su ordem y/o desorden (relativo).

Como efeito de ações passadas, o espaço social sugere algumas ações e proíbe outras. Entre essas ações umas remetem a produção. Lefebvre aponta o conceito de produção do espaço, tal como uma combinação de palavras que não tinha sentido algum, quando os filósofos dominavam o mundo dos conceitos. Segundo o autor, o espaço dos filósofos só pode ser criado por Deus.

O termo produção é analisado a luz do hegelianismo por Lefebvre (2013, p. 125):

La ideia (absoluta produce el mundo; después, la natureza produce el ser humano, el cual, a su vez, produce mediante sus luchas y su trabajo, simultáneamente, la história, el conocimiento y la conciencia de sí, esto es, el Espititu que reproduce la Idea inicial e final.

Dessa forma, o espaço social se produz e reproduz em contato com as forças produtivas, no curso do desenvolvimento. A produção do espaço ocorre a partir da prática social (espaço percebido pelos indivíduos), das representações do espaço (espaço concebido por cientistas, engenheiros, planejadores etc.) e do espaço representacional (espaço diretamente vivido pelos indivíduos).

O direito a natureza (o campo ou a natureza pura) na prática social há alguns anos se encontra em favor dos lazeres, contra o barulho, a fadiga, o universo concentracionista das cidades, consistindo na sua apropriação (LEFEBVRE, 1969, p. 67). O autor também adverte que não há um espaço social e sim vários espaços sociais, 
nenhum espaço chega a desaparecer e não se trata de uma consequência da lei do desenvolvimento desigual, mas de uma lei própria. Se tomado isoladamente, qualquer espaço é uma abstração. Conclui que o espaço social emerge em uma estrutura laminada (não homogênea), implicando, contendo e dissimulando as relações sociais.

$\mathrm{Na}$ prática social, a mercadoria turística manifesta-se atualmente como reutilização de formas passadas de produção ao consumo seletivo dos equipamentos culturais, derivados do processo de patrimonialização, repercutindo a representação do espaço por meio da visão de grupos hegemônicos de poder. Serpa (2007) chama de "festa-mercadoria" na qual se folcloriza e industrializa a história e a tradição dos lugares, roubando-lhes a alma, nas requalificações e revitalizações urbanas, em busca de vantagens comparativas.

Sobre a patrimonialização, Costa (2015, p. 37) esclarece que há um processo de revaloração dos lugares "uma potencial vertical de transformação de lugares singulares, uma generalidade que transforma particularidades e que é movida, dialeticamente, pelas últimas". A valorização do passado ocorre no contexto de uma construção destrutiva, que valoriza o dinheiro, gerando a desvalorização moral e ética dos lugares da vida humana e da sobrevivência natural biológica.

Às evidentes repercussões sobre o uso do litoral se acrescenta a lógica da patrimonialização dos espaços vividos, igualmente apropriados pelo turismo. Tal processo é distanciado da realidade dos moradores, alienados do direito de fruição dos espaços de representação, no qual o problema do morador deixa de ser o problema do turista.

Na reflexão de Trindade Junior (2018), cidades como Belém ao serem reinventadas, lançam um olhar do poder público sobre os velhos centros, abrigando-se na retórica da deterioração e do renascimento. Propõem-se cidades promissoras e atrativas, associadas a projetos preocupadas em eliminar o aspecto decadente, o estigma do medo, do perigo e da degradação física e social.

Nesse contexto, ecoa nessa reflexão, o discurso da patrimonialização como uma estratégia de modernização e logo como meio para o surgimento de um turismo de articulações globais. O mercado se instrumentaliza para isso, criando e reelaborando meios de produção de um espaço seletivo, cujas manifestações culturais, transformam a experiência e a memória, descontextualizando-as e as fragmentando em experiências a 
preços definidos nos "pacotes" de turismo e restritas por ingressos e pela venda de produtos agregados.

Em curso está uma tendência de globalização da cultura e a renovação das ideologias do patrimônio, onde o capitalismo contemporâneo associou à cultura uma nova e vigorosa racionalidade econômica (PAES-LUCHIARI, 2006). A perspectiva de um consumo turístico, certamente baliza o percurso do mercado sobre o patrimônio cultural. Essa condição revela-se ainda mais perigosa quando se trata da patrimonialização da natureza.

Tendo esse momento como marco de análise, o Brasil adentra no que Costa (2015, p. 35) classifica como um "brusco movimento universal de espetacularização e banalização pela cenarização progressiva dos lugares", capaz de promover o que denomina de dialética da construção destrutiva ou mercantilização e ressignificação dos lugares. Camilo e Bahl (2017) afirmam que o patrimônio cultural apresenta uma concepção de recurso econômico, capaz de gerar emprego e renda, associada ao crescimento do turismo, e à necessidade das pessoas em conhecerem cada vez mais a diversidade cultural e natural das regiões.

A valorização do patrimônio cultural proporciona cada vez mais uma nova organização do espaço por meio do consumo turístico dos espaços patrimonializados demonstra uma nova perspectiva de apropriação das cidades (PEREIRA, 2017). Essa produção do espaço em sua dimensão turística assume características de profunda desigualdade social, à medida que as facilidades, serviços públicos e equipamentos de lazer e cultura associados a natureza estão disponíveis somente a uma determinada faixa de renda.

Nesse sentido, o aprofundamento da globalização do capital, tais como a financeirização especulativa e a velocidade das transformações tecnológicas transformam em relações de consumo a necessidade de reaproximação do homem a terra e o reconhecimento da importância da natureza, na sua vida cotidiana. A primazia do valor de uso da natureza cede lugar ao valor de troca.

De outra maneira, uma redescoberta da natureza não pode ser uma corrida pela mercantilização dos lugares de memória, solenemente esquecidos pela vida urbana. A natureza tem um papel importante na construção do patrimônio cultural, além de seu papel como mercadoria, mas como parte integrante da sociedade na qual o turismo se 
apresenta como uma possibilidade e não uma determinação. Na perspectiva de Bahl e Nitsche (2016), muitas vezes a população é considerada apenas um 'objeto' componente do planejamento turístico, não participando e não conhecendo os efeitos que o turismo pode gerar no seu ambiente de vivência.

Santos (2014) explica que a história das relações entre sociedade e natureza é a da substituição de um meio natural por um meio artificializado, uma nova natureza. Para Taveira (2016, p. 12) existe uma relação dialética e de interdependência entre produção e consumo no atual contexto da atividade turística em que a dinâmica de produção e o consumo do espaço produzem e reproduzem a essência do próprio sistema capitalista de produção, e, por conseguinte, o modelo de desenvolvimento socioeconômico fortalecido pelo turismo, alicerçado nos moldes dos princípios fordistas de produção e do consumo de massa em espaços requalificados.

Todavia, pode ser dito que a lógica que designa a proteção do patrimônio cultural de valor ecológico e paisagístico, possibilita observar muito menos o seu valor de uso ou seu papel na reprodução da cultura e do espaço vivido e mais como uma estratégia de criação de valor de troca, materializada pela representação do espaço (espaço concebido nos planos e projetos de turismo).

\section{OS BENS NATURAIS TOMBADOS EM BELÉM DO PARÁ}

O Brasil é um dos signatários da Convenção para Proteção do Patrimônio Mundial, Cultural e Natural, produzida durante a $17^{\mathrm{a}}$ Conferência Geral da Organização das Nações Unidas para Educação, Ciência e Cultura (Unesco), realizada em Paris, em 1972 (COSTA, 2015), promulgada pelo Decreto 80.978 de 12 de dezembro de 1977 (BRASIL, 2006).. Com base nessa Convenção compreende-se que o "sítio do patrimônio natural" são as áreas de formação física, geográfica e biológica com valor estético ou científico excepcional e rara biodiversidade (BRASIL, 2008).

No Brasil, o principal instrumento de proteção do patrimônio cultural, adotado em todo o século XX foi o tombamento. A partir da década de 1930, essa prática foi concentrada na preservação de edificações, devido principalmente ao seu valor arquitetônico, como analisado por Ribeiro (2007). Entretanto, os tombamentos 
ocorridos na esfera federal, estadual ou municipal, em maior ou menor grau, ocultam profundos conflitos de interesses entre a conservação da memória e a capitalização de parcelas do solo.

No cenário estadual paraense, o principal marco legal da proteção de bens naturais é a Lei 5.629 de 20 de dezembro de 1990 que dispõe sobre a preservação do patrimônio histórico, artístico, natural e cultural do estado do Pará (PARÁ, 2002). Por meio do Artigo $4^{\circ}$ dessa lei foram instituídos, 4 livros de Tombo: Livro de Bens Naturais; Livro de Tombo de Bens Arqueológicos e Antropológicos; Livro de Tombo de Bens Imóveis e o Livro de Tombo de Bens Móveis.

Um dos objetivos principais do tombamento é o de impedir a destruição, demolição ou mutilação, só podendo sofrer qualquer intervenção com prévia autorização documentada junto ao Departamento de Patrimônio Histórico Artístico e Cultural do Estado. Na forma dessa lei, podem ser inscritos e protegidos no livro de Tombo de Bens Naturais, as paisagens, espaços ecológicos, recursos hídricos, monumentos e sítios ou reservas naturais, parques e reservas federais, estaduais e municipais (PARÁ, 2002).

Conforme Lista de Bens Tombados do Estado (PARÁ, 2015), muitos tombamentos ocorreram mesmo antes de ter sido sancionada a Lei 5629/1990. Os primeiros foram homologados desde 1981, mas publicados no Diário Oficial do Estado, a partir de 1982 (QUADRO 1). Entre 51 bens tombados em Belém, apenas 5 foram inscritos no livro de bens naturais, dos quais 2 ocorreram em 1982, 2 bens em 1983 e o último em 2004.

\begin{tabular}{|c|c|c|}
\hline $\begin{array}{c}\mathrm{N}^{\circ} \\
\text { processo }\end{array}$ & Descrição do Bem & $\begin{array}{c}\text { Data de } \\
\text { publicação }\end{array}$ \\
\hline $0471 / 81$ & $\begin{array}{l}\text { Conjunto Arquitetônico/Paisagístico do Museu Paraense Emilio } \\
\text { Goeldi, } \\
\text { Acervo e Coleções } \\
\text { Localização: Av. Magalhães Barata, } 376 \text { - São Braz. } \\
\text { Coordenadas geográficas: - } 1^{\circ} 27^{\prime} 7.19^{\prime \prime} ;-48^{\circ} 28^{\prime} 37.54^{\prime \prime}\end{array}$ & 02.07 .1982 \\
\hline $0505 / 81$ & $\begin{array}{l}\text { Conjunto Arquitetônico e Paisagístico do Bosque } \text { Municipal } \\
\text { Rodrigues Alves } \\
\text { Localização: Av. Almirante Barroso, 2453 - Marco. } \\
\text { Coordenadas geográficas: }-1^{\circ} 25^{\prime} 51.79^{\prime \prime} ;-48^{\circ} 27^{\prime} 19.16^{\prime \prime}\end{array}$ & 01.11 .1982 \\
\hline
\end{tabular}

Continua... 


\begin{tabular}{|c|c|c|}
\hline $\begin{array}{l}1705 / 82 \\
2111 / 82\end{array}$ & $\begin{array}{l}\text { Conjunto Paisagístico / Ecológico e Turístico das Áreas dos } \\
\text { Mananciais do Utinga e Entorno (lagos do Bolonha e Água Preta) } \\
\text { Localização: Área metropolitana de Belém entre a Rodovia BR } 316 \text { e } \\
\text { EMBRAPA - Curió - Utinga. } \\
\text { Coordenadas geográficas: }-1^{\circ} 25^{\prime} 33.63^{\prime \prime} ;-48^{\circ} 26^{\prime} 41.03 "\end{array}$ & 25.03 .1983 \\
\hline $0678 / 81$ & $\begin{array}{l}\text { Mangueiras e Samaumeiras existentes nas Ruas, Praças e Parques da } \\
\text { Área Metropolitana de Belém, bem como os Espécimes Existentes no } \\
\text { Município de Ananindeua. } \\
\text { Localização: Ruas, praças e demais logradouros públicos do } \\
\text { município de Belém. } \\
\text { Coordenadas geográficas: }-1^{\circ} 27^{\prime} 10.20^{\prime \prime} ;-48^{\circ} 29^{\prime} 42.30^{\prime \prime}\end{array}$ & 18.05 .1983 \\
\hline $\begin{array}{l}197583 / \\
2004\end{array}$ & $\begin{array}{l}\text { Ilha do Amor } \\
\text { Praça Princesa Izabel, } 3295 \text { - Localização: Distrito Administrativo de } \\
\text { Mosqueiro } \\
\text { Coordenadas geográficas: }-1^{\circ} 8^{\prime} 0.73^{\prime \prime} ;-48^{\circ} 28^{\prime} 0.89^{\prime \prime}\end{array}$ & 26.08 .2004 \\
\hline
\end{tabular}

FONTE: PARÁ (2015), adaptado pelo Autor.

O primeiro bem inscrito no livro de tombo de bens naturais como de natureza ecológica e paisagística foi o Conjunto arquitetônico/paisagístico, acervo e coleções do Museu Paraense Emílio Goeldi (PARÁ, 1995). O Museu teve origem a partir da fundação da Sociedade Filomática, criada em 6 de outubro de 1866, de caráter particular com apoio inicial do governo da Província, (BERTHO, 1994). Bastante frequentado desde o início do Século XX (FIGURA 1).

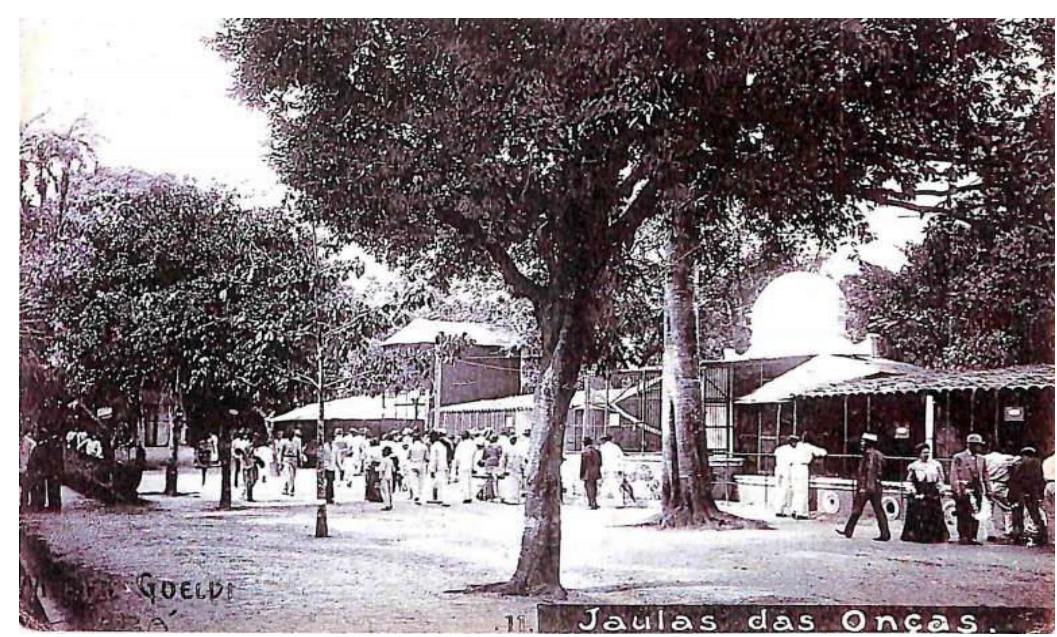

FIGURA 1 - VISITAÇÃO DO GOELDI, NO INÍCIO DO SÉCULO XX. FONTE: Pará (1998).

Desde os seus primeiros anos, estava entre os propósitos destacados do Museu a formação de um acervo arqueológico e etnográfico da Amazônia, possibilitado através de doações individuais de vários tipos de artefatos indígenas antigos e contemporâneos, o Museu iniciou seu acervo antropológico (BARRETO, 1992). 
Nota-se que apesar do seu rico acervo de história natural, o instrumento de tombamento foi utilizado como uma forma limitada de intervenção nesse aspecto. Sua relevância mais evidente encontra-se em seu acervo arqueológico e etnográfico tombado em 1940 pelo Patrimônio Histórico Nacional pelo Instituto do Patrimônio Histórico e Artístico Nacional (BRASIL, 2017) além de elementos arquitetônicos, como por exemplo, a edificação denominada de Rocinha ${ }^{1}$. Nesse Museu em uma área de 5,4 hectares (SOARES, 2009, p. 79). Conforme observado, suas instalações acolhem visitantes diários da cidade e turistas, mediante a cobrança de ingressos, onde podem acessar espaços de exposição e viveiros (FIGURA 2). Se junta ao acervo natural, monumentos e edificações históricas do século XIX e XX, loja de artesanato e livraria, café, venda de lanches, aviário e aquário.

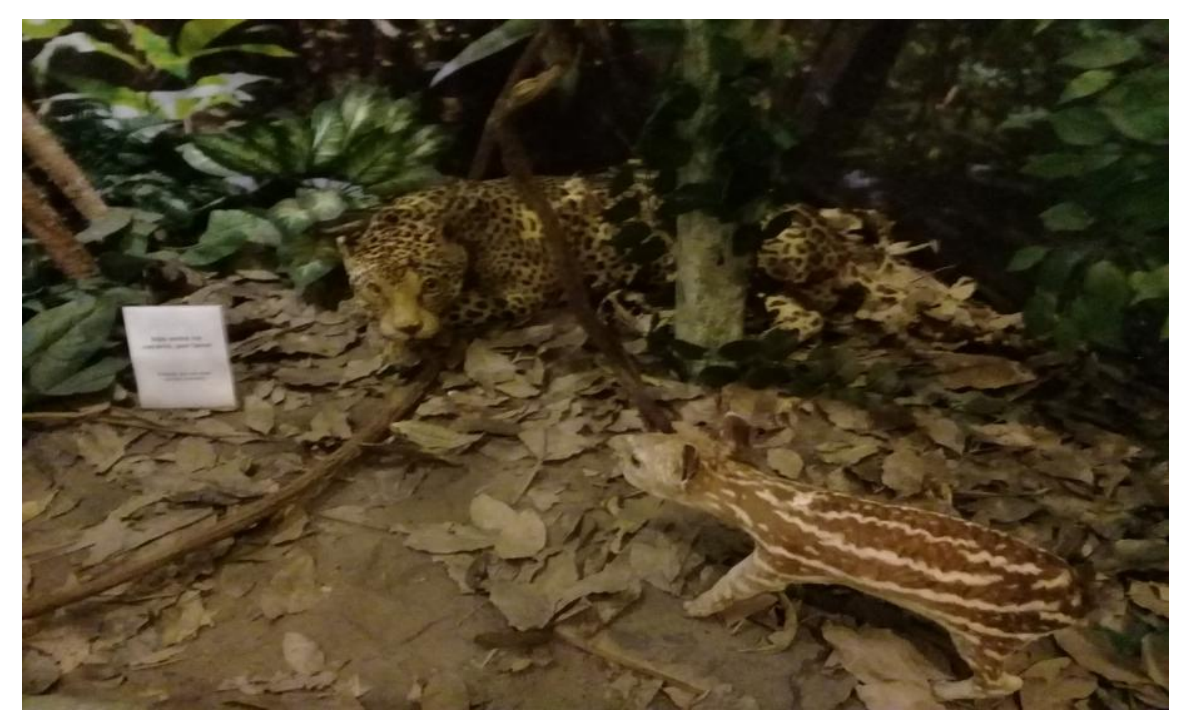

FIGURA 2 - EXPOSIÇÃO DE TAXONOMIA.

FONTE: Pesquisa de campo, 2018.

O segundo bem natural, também inscrito no livro de bens móveis, foi o Bosque Municipal Rodrigues Alves, com publicação em 1 de novembro de 1982 (PARÁ, 2015). Neste caso, mesmo tendo sua localização em uma área central da cidade replica aquilo que Ribeiro (2007) determina como resultado da tendência de reconhecimento de jardins como paisagens a serem protegidas. No bem em questão, se representa uma "rugosidade"(SANTOS, 2014) cuja concepção de raridade (HARVEY, 2016) do conjunto o permite como atração importante de Belém. 
Conforme pesquisado por Correa (2014) foi fundado no final do século XIX (FIGURA 3), o Bosque Rodrigues Alves foi projetado para ser uma espécie de reserva ambiental da região, como uma das medidas tomadas pela administração do intendente Antônio Lemos para garantir o embelezamento visual da cidade e frequentado pelas famílias mais abastadas da cidade.

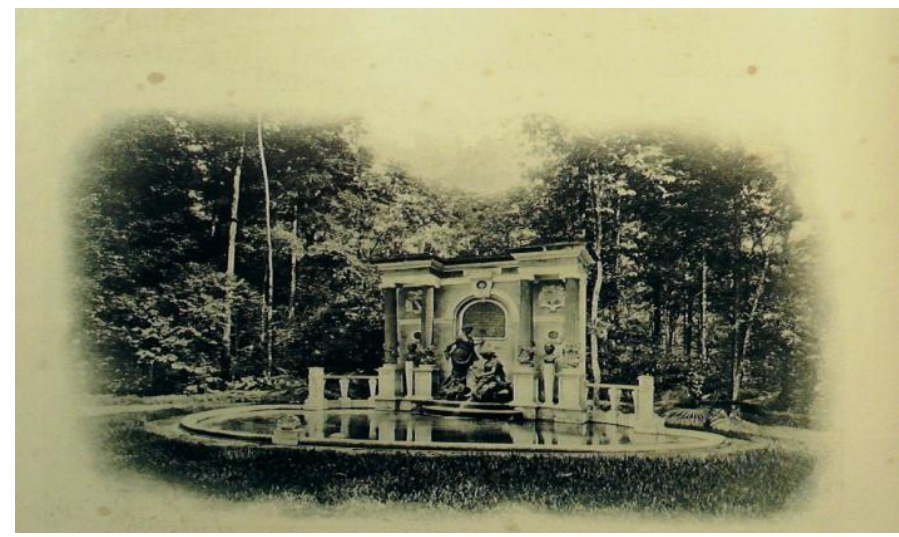

FIGURA 3 - BOSQUE MUNICIPAL, NO INÍCIO DO SÉCULO XX. FONTE: Pará (1908).

De acordo com Soares (2008), uma das principais preocupações urbanas do fim do século XIX e início do século XX era de embelezamento e modernização de Belém. Nesse contexto, o projeto do Bosque Municipal, de 1870 converteu uma área de reserva de floresta, posteriormente remodelado no ano de 1930, em uma das principais referências de lazer de Belém (SOARES, 2008). Conforme observado na visita de campo, foram identificados inúmeros problemas relacionados a falta de sinalização adequada, risco constante de quedas de árvores e a falta de manutenção de espaços evidenciadas na fachada e por onde os visitantes circulam (FIGURA 4).

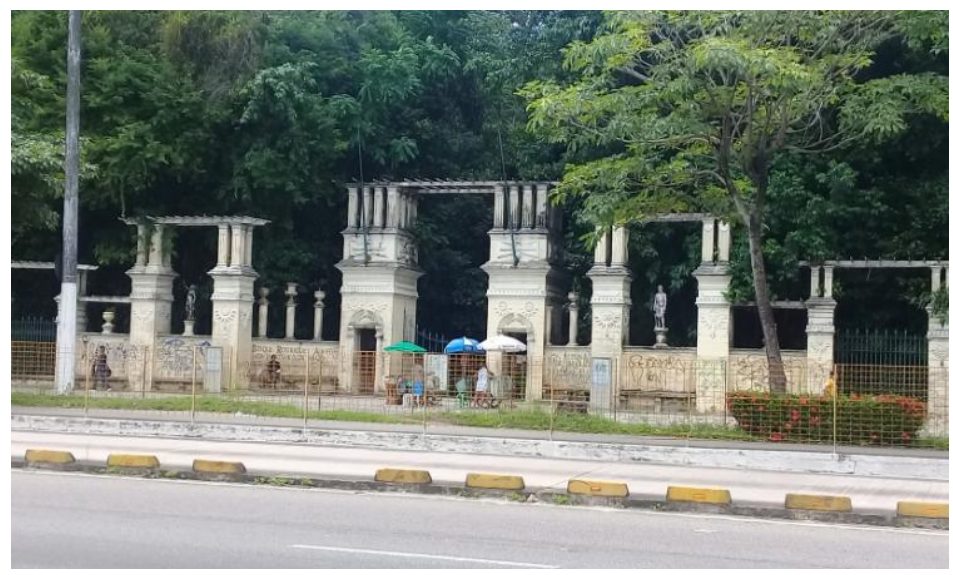

FIGURA 4 - FACHADA DO BOSQUE RODRIGUES ALVES. FONTE: Pesquisa de campo, 2018. 
Nos resultados da pesquisa de Correa (2014), o Bosque atualmente constitui um espaço muito utilizado para reunião e realização de cultos religiosos, sendo a maior parte dos visitantes oriundos da cidade de Belém. Em suma, esse bem cultural testemunha a necessidade de produção do espaço a partir de padrões hegemônicos de um período de grandes investimentos na região e cujas concepções remontam a um movimento que Giddens (2009) denominou de socialização da natureza, ou seja, produtos da decisão humana.

O Conjunto Paisagístico, Ecológico e Turístico das Áreas dos Mananciais do Utinga, foi tombado em 25 de março de 1983 (PARÁ, 2015). É possível perceber uma clara intenção de garantir a proteção das águas dos lagos Bolonha e Água Preta, como principais fontes do abastecimento urbano (FIGURA 5). Esse tombamento foi sobreposto pelo Decreto Estadual nº 1552/1993 (PARÁ, 1993) que criou o Parque Ambiental de Belém.
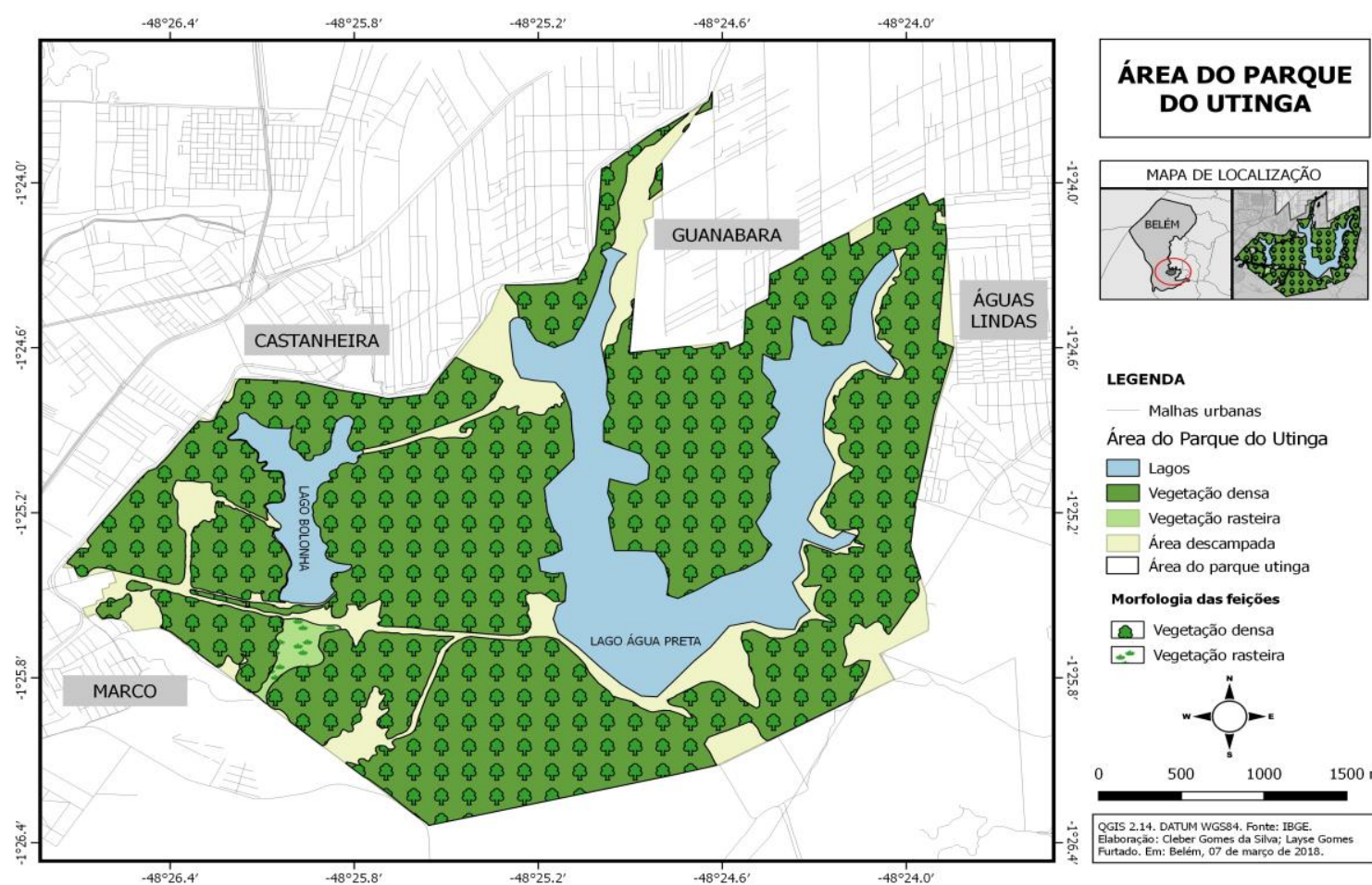

FIGURA 5 - ÁREA DO PARQUE DO UTINGA.

FONTE: Pesquisa de campo, elaborado por Cleber Gomes e Layse Furtado em 2018.

Essa condição ocasionou o esvaziamento na noção de valor cultural, por meio da substituição das ferramentas de proteção, legando o tombamento da área a uma situação de praticamente esquecimento de sua importância cultural. Em março de 2018 foi 
reestruturado pelo Governo do Estado, com investimentos de mais de 40 milhões de reais (PARÁ, 2018).

Conforme constatado, o parque estava oferecendo estrutura com centro de acolhimento equipado com café, loja de souvenir, auditório, banheiros e estacionamento para veículos (FIGURA 6; FIGURA 7). Contando com trapiches com vista para o Lago Água Preta e Bolonha. No lugar havia vagas de estacionamento pagas e podiam ser alugadas bicicletas, e realizar escaladas com rappel. Logo, entende-se que essa intervenção conduziu essa área a uma nova configuração da qual se encontra como um novo "produto turístico" de Belém.

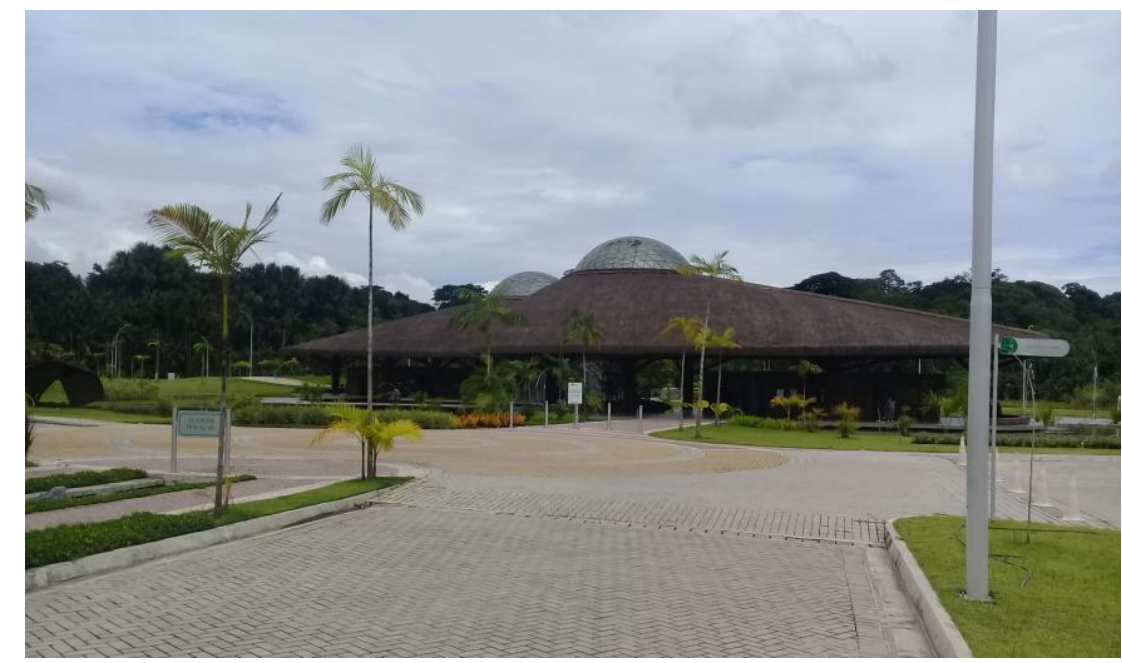

FIGURA 6 - ESPAÇO DE ACOLHIMENTO DO PARQUE DO UTINGA. FONTE: Pesquisa de campo, 2018.

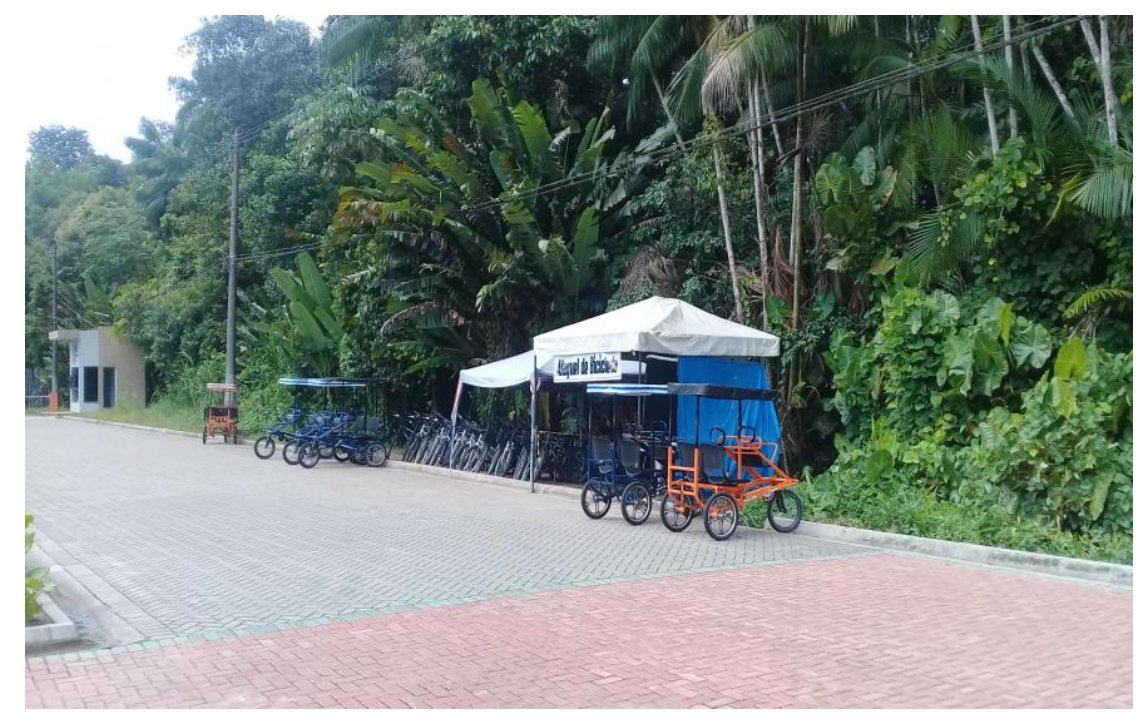

FIGURA 7 - PONTO DE ALUGUEL DE BICICLETAS DO PARQUE DO UTINGA. FONTE: Pesquisa de campo, 2018. 
Na perspectiva da produção do espaço, Lefebvre (2013, p. 127) argumenta que a natureza não pode produzir, apenas cria e o que ela cria de modo algum são produtos, porém proporciona somente valor de uso. Isto é, o valor de troca pode ser a manifestação de uma espécie de alienação da natureza ou de seu valor de uso, que aos poucos deixou de ser acessível a todos no processo de produção do espaço. Pode-se chamar esse processo de reformatação da área do Parque, o que Santos (1992) chama de natureza-espetáculo, substituta da natureza histórica e lugar de trabalho dos homens, confundida com os sistemas técnicos.

Além do patrimônio já mencionado, destaca-se o tombamento das mangueiras e samaumeiras, existentes nas ruas e praças de Belém, inscritas em 18 de maio de 1983, no livro de bens naturais (PARÁ, 2015). Apresenta-se como um recorte que traz referências a identidade da cidade, por muitos moradores referenciada como "cidade das mangueiras", devido aos diversos corredores de mangueiras que se formam nas vias centrais da cidade (FIGURA 8).

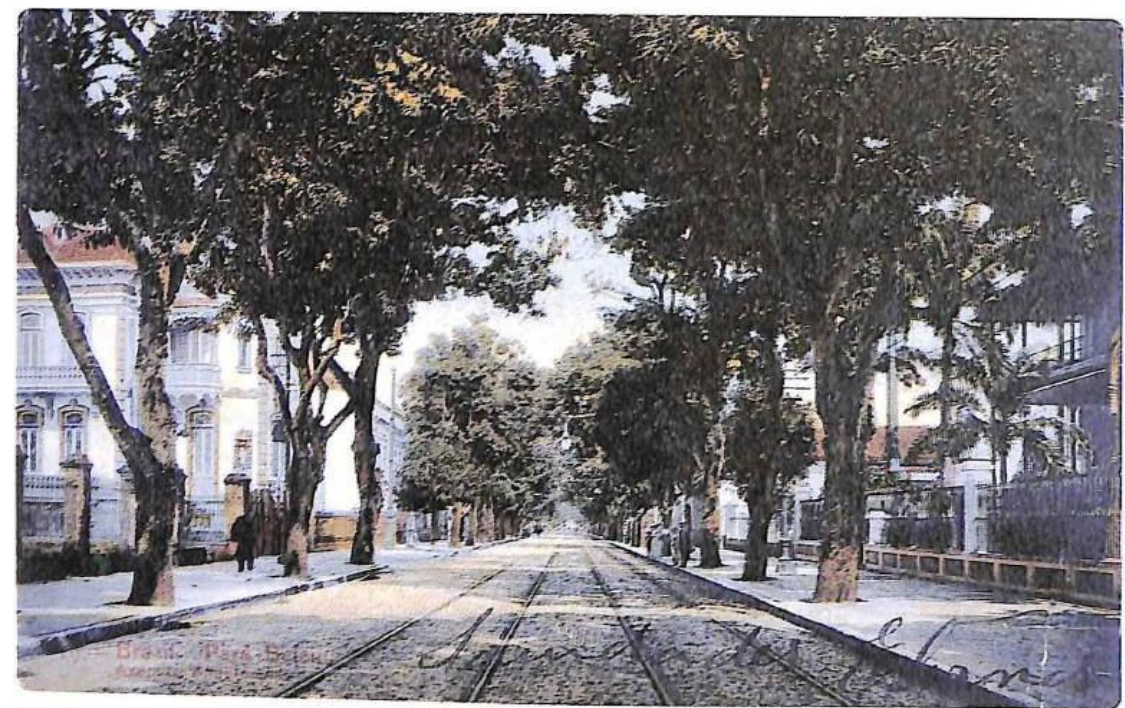

FIGURA 8 - CORREDOR DE MANGUEIRAS NO INÍCIO DO SÉCULO XX. FONTE: Belém da Saudade (PARÁ, 1998).

Todavia, essas espécies são um dos elementos que fizeram parte de um amplo projeto de arborização de Belém, entre o final do século XIX e início do XX, com a plantação extensiva de mangueiras (LOUREIRO E BARBOSA, 2011). Segundo Loureiro e Barbosa (2011), gradativamente se estabeleceu em Belém uma enorme diferença entre a área central, arborizada, graças à herança do passado (embora se tenha 
constatado muitas árvores doentes e envelhecidas) e uma área de expansão ou assentamentos ocupados pela população de baixa renda, em bairros desprovidos de verde nas ruas, e com raras praças que sirvam como pontos de lazer, recreação e encontro.

Destarte, aponta Loureiro e Barbosa (2011) em sua condição, onde as temperaturas são elevadas em todos os meses do ano, Belém deveria ter preservado em sua paisagem uma farta arborização, o que seria um fator importante para a qualidade de vida urbana. Apesar do tombamento, verificou-se que muitas dessas árvores são mutiladas e não recebem a mesma atenção ofertada aos bens imóveis. Algumas apresentavam raízes comprometidas pelo concreto e redes subterrâneas e copas constantemente podadas de forma radical ou até mesmo como área de despejo irregular de resíduos sólidos (FIGURA 9 ).

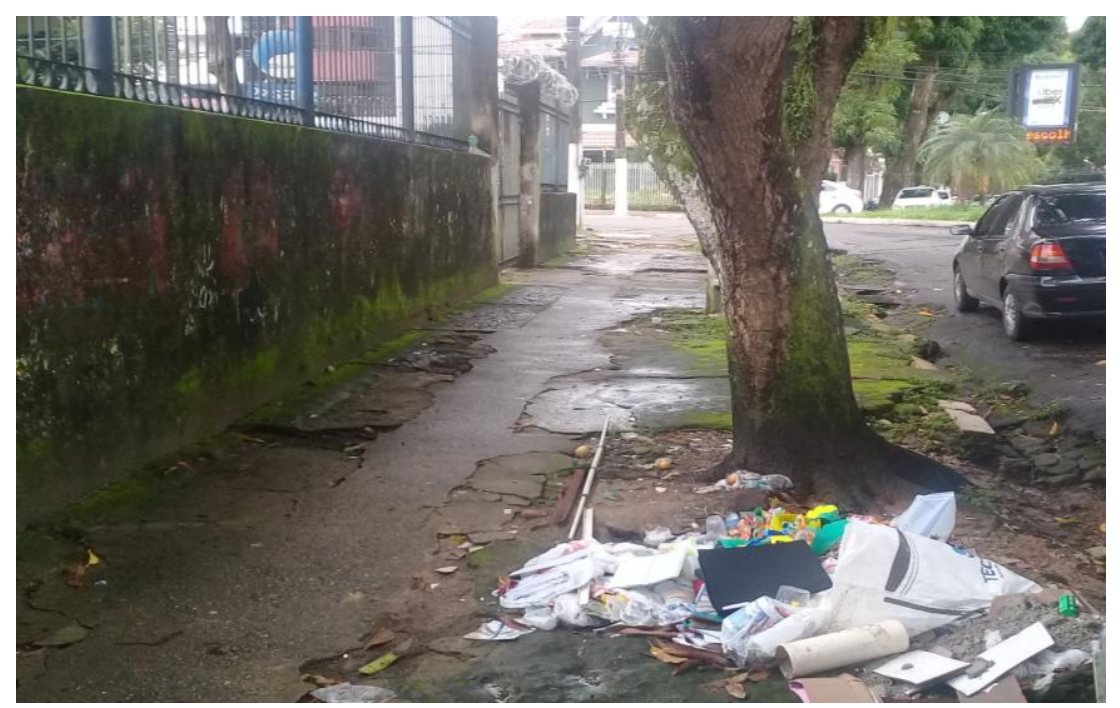

FIGURA 9 - DESPEJO DE RESÍDUOS SÓLIDOS EM CANTEIRO DE MANGUEIRA. FONTE: Pesquisa de campo, 2018.

O último bem natural tombado em Belém foi a Ilha do Amor, distrito de Mosqueiro (PARÁ, 2015). Trata-se de uma pequena formação de sedimentos, localizados na praia fluvial do Farol, por meio do qual se apresenta como referência de um importante conjunto turístico, formado por diversas praias.

Conforme Tavares (2007), a formação histórico espacial de Mosqueiro tem início no período colonial, a partir do atual Bairro de Carananduba, que era Nossa Senhora da Conceição do Benfica, foram erguidas no século XVIII as primeiras 
habitações coloniais, a fazenda Santana, na praia do Paraíso e a fazenda ou sítio Conceição. De acordo com a autora, com o ciclo da borracha vieram os ingleses da "Pará Electric Railways Company", alemães, franceses e americanos, de companhias como a "Port of Pará" e a "Amazon River". Gradativamente Mosqueiro se tornou um dos principais refúgios de lazer da sociedade paraense (FIGURA 10).

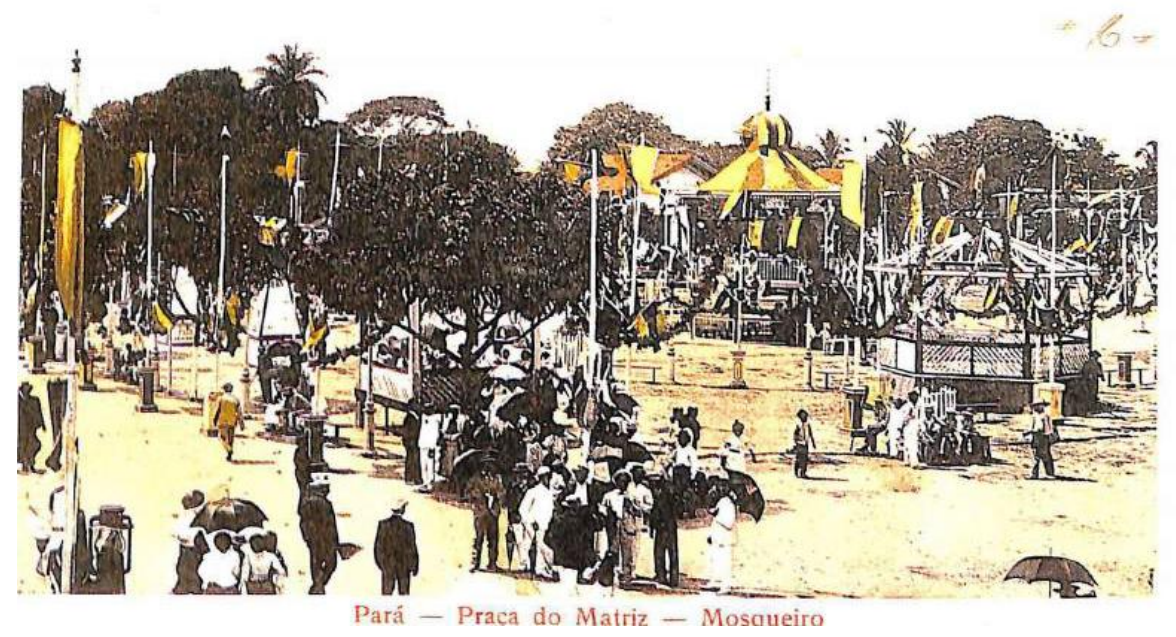

FIGURA 10 - PRAÇA DA MATRIZ EM MOSQUEIRO NO INÍCIO DO SECULO XX. FONTE: Pará (1998).

Uma série de transformações produziram um novo olhar sobre o lugar, como visto em Tavares (2007, p. 129):

\begin{abstract}
Os estrangeiros também começaram a fazer de Mosqueiro um refúgio nos finais de semana, feriados e períodos de férias. Não demorou para que os seringueiros e balateiros da região do Marajó seguissem os passos dos europeus e americanos, e começassem a erguer na orla suas casas de veraneio. Trapiches eram construídos em frente às residências para facilitar o transporte.
\end{abstract}

Conforme visto em Tavares et al. (2007), a partir dos anos de 1970, a construção da estrada e posteriormente a ligação definitiva entre Mosqueiro e o continente, através de uma ponte inaugurada em janeiro de 1976, contribuiu para tornar a ilha um dos principais núcleos de lazer e turismo de Belém. "No entanto, com o aumento do fluxo de veranistas e turistas, acelera-se a especulação imobiliária, o consumo dos locais turísticos e o aumento das pressões antrópicas sobre o meio ambiente.”(TAVARES et al., 2007, p. 129). 
Outros bens naturais localizados no interior do Estado também foram inscritos no livro de tombo de bens naturais. A relevância manifesta desses bens ocorreu muito como uma forma de valorização do seu uso turístico. No entanto, esse patrimônio sofre anualmente com o fluxo de visitantes que projeta uma série de problemas relacionados ao meio ambiente, sendo palco de problemas diversos relacionados a pressões sobre o mangue e dunas, por meio de ocupações irregulares e da circulação em massa de veículos e do despejo inadequado de resíduos sólidos (SILVA, 2014).

Praticamente, todos os bens inscritos como naturais em Belém são heranças de um período histórico de hegemonização e domesticação intensa da natureza, consagrando um modelo de exploração da região amazônica. Todavia, o maior problema da questão do tombamento dos bens naturais extrapola o debate sobre as reais intencionalidades da adoção desse instrumento e converge para suas consequências como mecanismo ao mesmo tempo de valorização cultural e de conservação da natureza. De outra maneira, identificou-se uma espécie de sobreposição entre política patrimonial e política ambiental. Isso tem prejudicado o desenvolvimento de ações relativas à memória dos lugares.

Além dos projetos de ocupação do território estarem historicamente atrelados ao comércio de suas riquezas naturais e ultimamente à expansão das fronteiras agropecuária e de exploração mineral, é inquestionável a importância dos bens naturais para a vida humana. Entretanto, na Amazônia, o valor da natureza ultrapassa os limites da simples contemplação ou da exploração dos recursos para fins econômicos. Sua importância cultural, como espaço vivido não pode ser reduzida a uma forma anexa da vida urbana ou a simples mercadoria.

Isso remete a necessidade de não considerar apenas a dimensão ecológica dos bens naturais, mas os diversos valores culturais que a integram, resultantes das relações da sociedade com a natureza. Isto é, o olhar do mercado, ao lançar-se sobre esses bens, não somente eleva a obra à condição de produto raro, como inibe as possibilidades de sua fruição pela população local. No caso dos bens naturais, isso pode representar a eliminação de laços afetivos. O parque, a praia, o bosque, simplesmente são arrancados de seu valor de uso e posteriormente "embalados" no prevalecimento do valor de troca e banalizados na prática do turismo. 
As próprias inscrições nos livros de tombo denotam uma função paisagística ou concebida, com predominância do ponto de vista estético e da necessidade de preservação de recursos baseada na concepção de uma "natureza intocável", como analisado por Diegues (2008).

Uma pista sobre as origens dessa abordagem pode ser encontrada em Gastal (2008, p. 3) que explica que:

Na cidade medieval murada, o que estivesse logo além dos muros é chamado de campo; floresta será o que ficar além do campo. O jardim demarcará o que estiver entre os muros; o jardim cercado é a Natureza sob controle, domada, que pode ser vivenciada para o prazer e a felicidade, aí presente a ideia de harmonia.

De outra forma, é importante resgatar a importância dos elementos naturais como espaço da história e memória. Ribeiro (2007) aponta a necessidade de perceber o bem em si, como entorno e ambiência para um sítio ou para que se tenham outros elementos exaltados, mediante a possibilidade de valorização da integração entre material e imaterial, cultural e natural.

No caso de elementos da natureza, não pode implicar em isolamento de um elemento ou unicamente escondê-lo na noção de conjunto. Logo, o que se apresenta como estrutura de referência para a proteção é a sua artificialização por meio da produção de equipamentos e serviços que permitam as relações econômicas. Hegemoniza-se dessa forma o espaço concebido (LEFEBVRE, 2013) cujas representações determinaram os tombamentos de bens naturais.

\section{CONSIDERAÇÕES FINAIS}

Tendo em vista os distintos contextos históricos e a importância e o valor de uso dos bens analisados, ao estabelecer a categoria de bens naturais, a Lei 5.629 de 1990 (PARÁ, 2002) conduziu a questão do patrimônio cultural a uma necessidade de aperfeiçoamento de suas formas de proteção. O tombamento, como um dos principais instrumentos de proteção tem entre suas principais características a determinação de um tipo de imobilização parcial ou integral dos bens culturais, cujas intervenções devem ser previamente autorizadas. Por si não garante a conservação dos valores de uso, pelo contrário, se configura como uma nova estratégia nas relações de produção do espaço. 
O efeito do tombamento é contraditório ao dinamismo da natureza, em sua condição orgânica de transformação. Os bens naturais não podem ser mantidos em sua forma "original". Por isso, apesar do reconhecimento legal, a maioria dos bens em questão podem apresentar dificuldades de inserção na agenda do patrimônio histórico, artístico e cultural.

Por outro lado, notou-se que a apropriação pelo turismo não se vincula nas atividades de interpretação da natureza em sua condição de patrimônio cultural, mas como representações "isoladas" de seu conteúdo social, na forma de produtos ou atrações para o turismo. Algumas intervenções são específicas para esse fim e as outras praticamente abandonadas aos movimentos turísticos espontâneos.

De outra maneira, considera-se que os bens naturais deveriam refletir-se na sociedade como fatores cruciais à referência da formação do povo paraense, como meios fundamentais não somente para o trabalho humano ou produto dele, mas igualmente ao imaginário e simbolismo que os evocam. Desse modo, a aplicação do instrumento de tombamento de bens naturais exige maior aprofundamento sobre questões relacionadas a sua eficácia e a como são interpretados e valorizados pela sociedade.

Os bens naturais podem e devem ser interpretados como um conjunto formado a partir de referências coletivas de aspectos da vida material e espiritual de determinados grupos. Sobretudo, são tecidos inalienáveis da ação de indivíduos, portadores de conhecimentos que se vinculam ao ambiente natural. Assim a natureza-histórica define as particularidades dos lugares e que consequentemente a valoriza como espaço vivido.

Enfim, é possível que os tombamentos dos bens naturais tenham sido impulsionados por sua relação dialética com um modelo cultural hegemônico de acumulação de capital, revestido novamente por um processo de patrimonialização, no qual a natureza é considerada apenas como um recurso.

\section{REFERÊNCIAS}

BARRETO, M. V. História da pesquisa arqueológica no Museu Paraense Emílio Goeldi. Boletim do Museu Paraense Emílio Goeldi, série Antropologia, Belém, v. 8, n. 2, p. 203-294, 1992. 
BERTHO, A. M. de M. O Museu Paraense Emílio Goeldi no contexto cultural da Amazônia. In: SILVEIRA, I. M. da.; DANLAO, M. A. (Orgs.). A Amazônia e a crise da modernização. Belém: MPEG, 1994.

BRASIL. Bens tombados e processos de tombamento em andamento - Pará. Instituto do Patrimônio Histórico Artístico Nacional - IPHAN. 2017. Disponível em: $<$ http://portal.iphan.gov.br/uploads/ckfinder/arquivos/Para_bens_tombados_novemb ro_2017.pdf $>$. Acesso em: 10 de janeiro de 2018. 1988.

Constituição da República Federativa do Brasil. Brasília: Senado Federal,

. Coletânea de Leis sobre preservação do Patrimônio. Rio de Janeiro: IPHAN, 2006.

Patrimônio mundial: fundamentos para seu reconhecimento - A convenção sobre proteção do patrimônio mundial, cultural e natural, de 1972: para saber o essencial. Brasília, DF: IPHAN, 2008.

CAMILO, I; BAHL, M. Desenvolvimento do turismo baseado em elementos culturais Turismo \& Sociedade, Curitiba, v. 10, n. 1, p. 1-12, 2007.

CASTRO, E. M. R. Urbanização, pluralidade e singularidades das cidades amazônicas. In: (Org.). Cidades na floresta. São Paulo: Annablume, 2008, p. 13-39.

CORRÊA, R. L. Periodização da rede urbana da Amazônia. In: Revista Brasileira de Geografia, ano, 49, n. 3. Rio de Janeiro, 1987, p. 39-68.

CORREA, H. V. A representação social de áreas verdes em cidades: o caso Bosque Rodrigues Alves - Jardim Botânico da Amazônia. Revista Margens Interdisciplinar. v. 8, n. 11, p. 70-88, ago. 2014.

COSTA, E. B. Cidades da patrimonialização global. Simultaneidade totalidade urbana - totalidade-mundo. São Paulo: Humanitas, Fapesp, 2015.

DIEGUES, A. C. O mito moderno da natureza intocada. 6 ed. São Paulo: Editora Hucitec, 2008.

GASTAL, S. Da paisagem natural à paisagem cultural, um percurso de presençaausência da natureza. In: XXXI CONGRESSO BRASILEIRO DE CIÊNCIAS DA COMUNICAÇÃO. Anais... Natal, RN, 2 a 6 de setembro de 2008.

GIDDENS, A. A constituição da sociedade. 3. ed. São Paulo: Editora WMF Martins Fontes, 2009.

As consequências da modernidade. Tradução de: Raul Fiker. São Paulo: Editora Unesp, 1991. 
HARVEY, D. As 17 contradições e o fim do capitalismo. Tradução de: Rogério Betonni. São Paulo: Boitempo, 2016.

HAESBAERT, R. O mito da desterritorialização: do "fim dos territórios" à multiterritorialidade. 3. ed. Rio de Janeiro: Bertrand Brasil, 2006.

LEFEBVRE, H. A revolução urbana. Tradução de Sergio Martins. 1. Reimp. Belo Horizonte: Editora UFMG, 2002.

La producción del espacio. Tradução e introdução de Emilio Martínez. Madrid: Capitán Swing, 2013.

Introdução à Modernidade. RJ: Paz e Terra, 1969.

LOUREIRO, V. R.; DA SILVA BARBOSA, E. J. Cidade de Belém e natureza: uma relação problemática? Novos Cadernos NAEA, v. 13, n. 1, p. 105-134, Julho 2011.

NORA, P. Entre história e memória: a problemática dos lugares. Revista Projeto História. São Paulo, v. 10, p. 7-28, 1993.

NITSCHE, L. B ; BAHL, M. Contribuições de base geográfica cultural para o estudo do turismo em comunidades locais. Turismo \& Sociedade. Curitiba, v. 9, n. 2, p. 1-18, maio-agosto de 2016.

PAES-LUCHIARI, M. T. D. Patrimônio cultural: uso público e privatização do espaço urbano. Geografia. Rio Claro, v. 31, n.1, p.47-60, janeiro-abril de 2006.

PARÁ. Decreto estadual $\mathbf{n}^{\mathbf{0}}$. 1.552, de 3 de maio de 1993. Dispõe sobre a Criação do Parque Ambiental de Belém e dá outras providências. Disponível em: $<$ https://ideflorbio.pa.gov.br/wp-content/uploads/2015/10/1993-Decreto-Estadual-15521993-Cria-Parque-Ambiental-de-Bel\%C3\%A9m.pdf>. Acesso em: dezembro de 2018.

. Governo do Estado. Livro de tombo de Bens Naturais, Belém: Secult, 1995.

. Governo do Estado. Álbum do Estado do Pará 1901-1909. Paris: Champonet, 1908, p.45.

. Governo do Estado. Belém da Saudade: A Memória de Belém do início do século em Cartões - Postais. 2. ed rev. aum. Belém. SECULT, 1998, 278 p.

Inauguração do Parque Estadual do Utinga atrai a população paraense. Belém: Ideflor-Bio.16 de março de 2018. Disponível em: $<$ https://ideflorbio.pa.gov.br/2018/03/inauguracao-do-parque-estadual-do-utinga-atrai-apopulacao-paraense/.> . Acesso em: Dezembro de 2018.

Secretaria Executiva de Cultura. Departamento de Patrimônio Histórico, Artístico e Cultural. Tombamento: Lei Estadual n 5629/1990. Belém, DPHAC, 2002. (Informar para Preservar). 
Secretaria de Estado de Cultura. Departamento de Patrimonio Historico Artístico e Cultural - DPHAC. Patrimônio Cultural Tombado. Belém. Janeiro de 2015. Disponível em:

<http://www.aedmoodle.ufpa.br/pluginfile.php?file=/175047/mod_page/content/12/Listag em\%20bens\%20Tombados\%20Capital\%20-\%202012.pdf>. Acesso em: Julho de 2018.

PEREIRA, N. S. S. Patrimônio cultural, turismo e ordenamento territorial. Turismo \& Sociedade. Curitiba, v. 10, n. 3, p. 1-14, 2017.

RIBEIRO, R. W. Paisagem cultural e patrimônio. Série Documentação e Pesquisa do IPHAN. Rio de Janeiro, IPHAN, 2007.

SANTOS, M. Pensando o espaço do homem. 5. ed. São Paulo: Edusp Editora da Universidade de São Paulo, 2009.

A redescoberta da Natureza. Estudos Avançados, São Paulo, v. 6, n. 14, p. 95-106. 1992.

A natureza do espaço: técnica e tempo, razão e emoção. 4.ed. 8. reimpr. São Paulo: Editora da Universidade de São Paulo, 2014.

SCHMID, C. A teoria da produção do espaço de Henri Lefebvre: em direção a uma dialética tridimencional. Tradutores: Marta Inez Medeiros Marques; Marcelo Barreto GEOUSP - espaço e tempo, São Paulo, n. 32, p. 89- 109, 2012.

SERPA, A. Cultura de massa versus cultura popular na cidade do espetáculo e da "retradicionalização". Espaço e Cultura, UERJ, Rio de Janeiro, n. 22, p. 79-96. 2007.

SOARES, A. C. L. Impactos da urbanização sobre parques públicos: estudo de caso do Parque Zoobotânico do Museu Goeldi (Belém - PA). Orientador: Eleanor Gomes da Silva Palhano. Dissertação apresentada ao Programa de Mestrado em Desenvolvimento e Meio Ambiente Urbano da Universidade da Amazônia - UNAMA. Belém, 2009.

SOARES, C. G. As formas de morar de Belém da Belle-Epóque (1860-1910). Orientador: Geraldo Mártires Coelho. Dissertação apresentada ao Programa de PósGraduação em História. Universidade Federal do Pará, Belém. 2008.

SILVA, C. G. Acondicionamento e coleta de resíduos sólidos: um estudo sob a perspectiva dos prestadores de serviços turísticos da Praia do Atalaia-PA. TurismoVisão e Ação, v. 16, n. 1, p. 144-166, 2014.

TAVARES, M. G. da C. A Amazônia brasileira: formação histórico-territorial e perspectivas para o século XXI. GEOUSP - Espaço e Tempo, São Paulo, n. 29 Especial, p. 107-121, 2011. 
TAVARES, M. G. da C. GOMES, K.S.; DA COSTA, M. A. F; RIBEIRO, W. O.. Turismo e desenvolvimento local em uma ilha fluvial na Região Metropolitana de Belém: o caso da ilha de Mosqueiro na Amazônia brasileira. Revista Universitária de Geografia. Bahía Blanca, v. 16, n. 1, 2007.

TAVEIRA, M. da S. Identidades cultural e turística de São Miguel do Gostoso, Rio Grande do Norte (RN), Brasil . Turismo \& Sociedade. Curitiba, v. 9, n. 1, p. 1-22, janeiro-abril de 2016.

TRINDADE JUNIOR. S. C. Um "skyline" em mutação: o velho centro e as transformações urbanas em Belém. Novos Cadernos NAEA, Belém, v. 21, n. 1, p. 5778. 2018.

Recebido em: 09-08-2018.

Aprovado em: 08-09-2018.

Versão finalizada para publicação em: 17-01-2019. 